\title{
Reflexões sobre o Ensino de Mecânica Quântica nos Cursos de Graduação em Física a partir de Revisão Sistemática
}

\section{Reflections on the Teaching of Quantum Mechanics in Undergraduate Physics Courses from Systematic Review}

\author{
Rafaelle da Silva Souza ${ }^{\circledR}$ Brasil \\ Ileana Maria Greca ${ }^{\circledR}$ Espanha \\ Indianara Silva ${ }^{\circledR}$ Brasil \\ Elder Sales Teixeira ${ }^{\circledR}$ Brasil
}

Este artigo tem por objetivo descrever e analisar estudos empíricos realizados na área de concentração no que tange ao ensino de Mecânica Quântica (MQ) nos cursos de graduação em Física. Foram localizados 9 estudos indexados nas bases de dados Education Resources Information Center, Web of Science, Scopus e Springer, referentes ao período de 2001 a 2018. Para cada estudo foram consideradas suas características gerais, o conteúdo ministrado, as bases teórico-metodológicas e a síntese dos resultados. São poucos os estudos sobre o ensino de MQ em contexto de componente curricular, sobretudo no Brasil. Além da escassez, não há rigor na padronização metodológica em relação a estrutura do processo de ensino-aprendizagem investigado, o que torna difícil a comparação entre os estudos encontrados. As diferenças metodológicas contribuem para a grande diversidade de possibilidades para o ensino de MQ. Entretanto, apesar de todos os problemas, verifica-se a necessidade de investir na compreensão conceitual com atenção aos impactos gerados ao processo de formação dos estudantes. Considerando as análises realizadas, recomendam-se estudos cuidadosamente desenhados para esclarecer a relação entre a implementação de inovações didáticas condizentes com as necessidades e o interesse dos estudantes. Embora exista algumas revisões nessa área de pesquisa, ainda são insipientes o fomento de subsídios para orientar a tomada de decisão no tocante à formulação de cursos de MQ adequados à realidade de sala de aula.

Palavras-Chave: Mecânica Quântica; Componente Curricular; Graduação em Física.

This paper analyzes previous empirical studies on the teaching of Quantum Mechanics (QM) to describe its context in the curriculum of undergraduate courses in Physics. Nine studies from 2001 to 2018 were found indexed on the databases of Education Resources Information Center, Web of Science, Scopus, and Springer. For each study, we considered general characteristics, the content taught, and the theoretical-methodological bases. There are few studies on the teaching of QM in the curriculum, especially in Brazil. In addition to this scarcity, the lack of methodological standardization concerning the structure of the investigated teaching-learning process makes a comparison with these 
studies difficult. The methodological differences contribute to the great diversity of possibilities for teaching QM. However, despite the problems, there is a need to invest in conceptual understanding with attention to the impacts generated along the students' training process. In conclusion, we recommend studies on the relationship between the implementation of educational innovations and the needs and interests of students. Thus, our study is designed as an aid to guide decision-making regarding the formulation of more appropriate QM courses for classroom reality.

Keywords: Quantum Mechanics; Curricular Subject; Undergraduate Physics Courses.

\section{Introdução}

Estudos, práticas e investigações voltadas para o processo de ensino-aprendizagem da Mecânica Quântica (MQ) ganharam notoriedade nas últimas décadas, principalmente por se tratar de um dos ramos mais importantes da Física no século XX (Akarsu, 2010). As produções sobre o ensino de MQ suscitam questões não somente didáticas e pedagógicas, mas também se hibridizam com questões ontológicas, epistemológicas, historiográficas, experimentais entre tantas outras. Como indicativo da crescente importância do tema, vale o destaque ao livro "Teoria quântica: estudos históricos e implicações culturais", vencedor da categoria Ciências Exatas do Prêmio Jabuti 2011 (Freire Jr., Pessoa Jr., \& Bromberg, 2010).

Em trabalho de revisão de literatura, Greca e Moreira (2001) já apresentavam justificativas para a inserção da MQ nos currículos de Física e apontava para um quase consenso entre professores e pesquisadores acerca da necessidade de introduzir a teoria quântica nos cursos tanto de ensino médio como de graduação. Nessa investigação, contudo, os autores constatam um número escasso de pesquisas, tanto das concepções prévias dos estudantes sobre conceitos quânticos, quanto dos resultados de implementações didáticas testadas em sala.

Pereira e Ostermann (2009), quelevaram em conta trabalhos publicados entre 2001 e 2006, referentes ao ensino médio e ensino superior, constataram que, apesar do notável aumento relativo de publicações de física moderna e contemporânea que apresentam resultados de pesquisa, a maioria referia-se à bibliografia de consulta para professores, e que, apesar de haver um número razoável de estudos envolvendo propostas didáticas inovadoras, poucos trabalhos investigavam os mecanismos envolvidos no processo de construção de conhecimento relativos a temas de física moderna. Até 2009, segundo Pantoja et al. (2011), observa-se um aumento progressivo no número de publicações de trabalhos na área, no entanto, faltam aqueles que analisem as concepções dos estudantes e não se centrem apenas em construção de instrumentos.

Ao revisar trabalhos publicados entre 2010 e 2016, Rocha et al. (2018) afirmam que há uma preocupação dos pesquisadores com a implementação das propostas didáticas e o estudo da compreensão e concepção dos estudantes acerca dos conceitos quânticos abordados. Logo, observam-se avanços nesse sentido. Os autores destacam 
que há expressivo interesse, quase metade dos trabalhos analisados tem relação direta ou indireta com o ensino de física moderna e contemporânea no nível secundário.

Ao apresentar um estado da arte desse campo de conhecimento científico, com trabalhos entre 1986 a 2016, Cuesta (2018) afirma que a ausência de reflexão conceitual sobre a física quântica gera dificuldades no processo de formação dos estudantes, e uma alternativa na busca por melhorias seria repensar seu ensino e a formação inicial e continuada dos professores de ciências. Em consequência, são sinalizados alguns esforços para ensinar a MQ de uma maneira mais conceitual aos estudantes de graduação e ensino médio (Krijtenburg-Lewerissa et al., 2017). Essas revisões evidenciam complexidade, atualidade e a busca por diferentes formas de apresentação da MQ visando a atualização curricular.

No presente artigo uma nova revisão é realizada cujo objetivo foi descrever e analisar estudos empíricos realizados pela área no que tange ao ensino de MQ nos cursos de graduação em Física. Trata-se de uma investigação que visa sintetizar as evidências relevantes disponíveis sobre as pesquisas em ensino de MQ analisando os resultados empíricos obtidos em sala de aula. Essa questão é importante por fornecer indícios particularmente úteis a professores e pesquisadores da área, uma vez que se observa resultados conflitantes e/ou coincidentes que motivam temas de investigações futuras.

No cenário contemporâneo tem-se proposto metodologias e estratégias para o ensino da MQ, mas são escassas as investigações sobre o ensino de MQ em contexto de componente curricular, sobretudo no Brasil. Além da escassez, existe pouca padronização metodológica em relação a estrutura do processo de ensino-aprendizagem investigado, o que torna difícil a comparação entre si. As diferenças metodológicas contribuem para a grande diversidade de possibilidades para o ensino de MQ. Entretanto, apesar de todos os problemas, verifica-se a necessidade de investir na compreensão conceitual com atenção aos impactos gerados ao processo de formação dos estudantes.

Estas são algumas das razões pelas quais é importante analisar estudos empíricos no referido contexto e por sua vez aprofundar nas discussões que apresentam possibilidades de avanço, visando assim ao fomento de subsídios para orientar a tomada de decisão no tocante à formulação de cursos de MQ adequados à realidade de sala de aula. A compreensão das abordagens para ensinar MQ em nível de graduação pode ser útil no desenvolvimento de ferramentas instrucionais eficazes para ajudar os estudantes a aprender a MQ.

\section{Percurso metodológico de revisão sistemática}

O método da revisão sistemática da literatura foi utilizado. Esse método consiste na revisão retrospectiva de artigos científicos cujo critério para sua delimitação foi serem estudos voltados para cursos de graduação em Física e realizados no contexto de um componente curricular de MQ. Convém registrar que a presente revisão de literatura não tem a pretensão de esgotar a extensa bibliografia relacionada ao ensino de MQ, mas analisar esse contexto específico. 
O levantamento bibliográfico foi operacionalizado mediante busca eletrônica de artigos indexados nas bases de dados Education Resources Information Center, Web of Science, Scopus e Springer - estas estão entre as principais bases de dados na área de Educação - que incluem revistas como: American Physical Society (APS), International Journal of Science Education (IJSE), Science Education (SE), American Journal of Physics (AJP), Foundations of Physics (FP), Physics Teacher (PT), Physics Education (PE), European Journal of Physics (EJP), Journal of Physics (J Phys), Investigações em Ensino de Ciências (IENCI), Enseñanza de las Ciencias (Enz), Revista Brasileira de Ensino de Física (RBEF), Caderno Brasileiro de Ensino de Física (CBEF), entre outras. Para a combinação de descritores (palavras-chave), de modo que obtivéssemos apenas os artigos com similaridade ao conteúdo pretendido, foram consideradas: Modern Physics; Quantum Mechanics; Physics Teaching; Teaching Learning.

Esse processo permite a coleta de informações a partir da consulta de literatura especializada em uma área específica de investigação; e de forma sistemática e crítica, elencam-se os principais resultados da área em foco, todos os quais podem ser extremamente pertinentes para os investigadores (Bennett et al., 2005). A estratégia metodológica usada nesta revisão foi baseada fortemente nos artigos Teixeira et al. (2012a) e Teixeira et al. (2012b). A seleção de estudos seguiu-se à definição de critérios de inclusão/exclusão (Figura 1).

\begin{tabular}{|c|c|c|}
\hline \multicolumn{2}{|c|}{ Critérios de seleção } & Critérios de inclusão \\
\hline \multirow{3}{*}{1} & Data da publicação & A partir dos anos $2000^{1}$ \\
\hline & Formato & Artigos completos \\
\hline & Idioma & Português, Inglês e Espanhol \\
\hline 2 & \multirow[b]{2}{*}{ Desenho do estudo } & Estudos que avaliem características do processo ensino-aprendizagem \\
\hline 3 & & $\begin{array}{l}\text { Cursos de graduação em Física } \\
\text { Estudos realizados no contexto de um componente curricular } \\
\text { Discussão de perspectivas curriculares em contexto de sala de aula }\end{array}$ \\
\hline \multicolumn{3}{|r|}{ Critérios de exclusão } \\
\hline 1 & \multirow{3}{*}{$\begin{array}{l}\text { Não fazem parte } \\
\text { dessa revisão }\end{array}$} & $\begin{array}{l}\text { Estudos sob a forma de dissertações, capítulos de livro, trabalhos } \\
\text { apresentados em conferências ou relatórios de avaliação }\end{array}$ \\
\hline 2 & & $\begin{array}{l}\text { Resultados de pesquisa sobre fundamentos da Mecânica Quântica } \\
\text { Artigos voltados para o Ensino Médio }\end{array}$ \\
\hline 3 & & $\begin{array}{l}\text { Propostas didáticas e/ou relatos de experiências didáticas centrados em } \\
\text { um ou mais conteúdo que não estejam em contexto de componente } \\
\text { curricular }\end{array}$ \\
\hline
\end{tabular}

Figura 1. Critérios de inclusão/exclusão

$\mathrm{Na}$ sequência, foram selecionados os artigos alinhados aos critérios de seleção e o refinamento ocorreu ao longo do processo até se chegar ao número final de artigos

1 O recorte temporal se justifica por desejarmos observar os resultados de pesquisas das duas últimas décadas com garantias de atualidade para o campo de pesquisa em questão. 
incluídos nesta revisão. O processo de inclusão/exclusão está demonstrado na Figura 2.

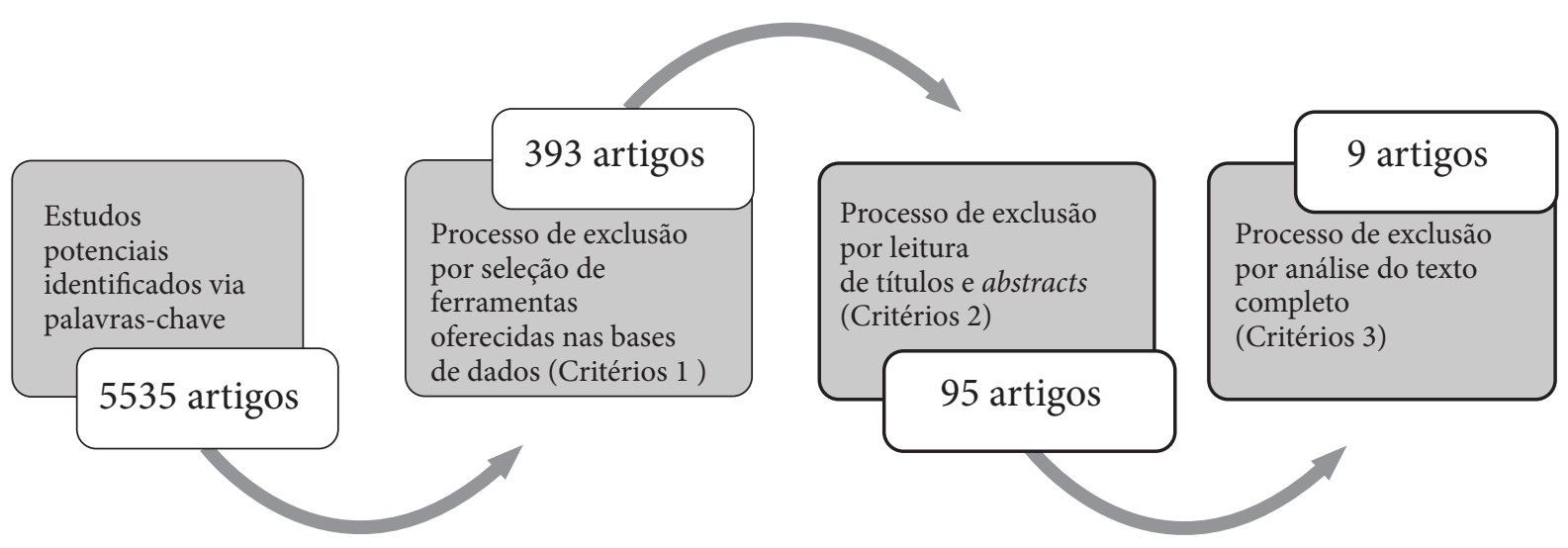

Figura 2. Processo de seleção dos estudos

A consulta às bases de dados gerou, inicialmente, um total de 5535 resultados de estudos indexados em periódicos. Depois, usando ferramentas próprias destas bases (somente artigos completos, publicados em português, inglês ou espanhol) restaram 393 artigos, dos quais foram excluídos 298 pela leitura do título e abstract. Com o quantitativo de 95 artigos aplicamos o critério de seleção 3 (Figura 1). Nesse momento, foi iniciado o processo de caracterização geral dos estudos.

No processo de leitura dos artigos ( $\mathrm{n}=95)$, foi contabilizado apenas 9 estudos voltados para cursos de graduação em Física e realizados no contexto de um componente curricular de MQ. Sendo que 85 artigos discorriam sobre propostas didáticas e/ou relatos de experiências didáticas e 1 artigo não apresentava intervenção em contexto de sala de aula, ou seja, apresentava somente a parte de preparação de material didático. Reconhecemos que, apesar de 86 artigos não configurarem proposta de componente curricular, muitos indícios substanciais podem contribuir para discutir as dificuldades de compreensão dos estudantes e, consequentemente, o processo de ensino-aprendizagem da MQ. E, sobre isso, recomendamos fortemente a leitura das revisões da literatura mencionadas, as quais incluem vários desses artigos contabilizados.

Desse modo, foram adquiridos 9 estudos através da seleção de artigos indexados em periódicos publicados no período de 2001 a 2018. Selecionados os estudos que compõem o corpus que delimitou o material de análise da revisão, procedeu-se à descrição geral dos artigos e o tratamento dos dados: características gerais dos estudos, conteúdo ministrado, bases teórico-metodológicas e síntese dos resultados. As etapas seguidas para o procedimento de análise temática envolveram: exploração do material (organização dos dados através da leitura de cada artigo com sistematização das principais ideias sob a forma de tabelas/quadros); caracterização das bases teórico-metodológicas presentes nas investigações, instrumentos didáticos, as dificuldades predominantes e as propostas para superação. 


\section{Resultados}

\section{Visão geral dos estudos consultados}

Inicialmente, chamamos atenção para os resultados gerais encontrados na busca realizada, com os descritores supracitados, acerca de estudos sobre o ensino da MQ nos cursos de graduação em Física - 95 artigos foram previamente selecionados. Na Tabela 1, é apresentada uma síntese dos resultados quantitativos dessa seleção, contendo o número de artigos encontrados por década e por ano, bem como o número de artigos por revista, em cada ano e no total.

Tabela 1. Quantificação de trabalhos incluídos na seleção, por década, por ano e por revista

\begin{tabular}{|c|c|c|c|c|c|c|c|c|c|c|c|c|c|c|c|c|c|c|}
\hline \multirow[b]{2}{*}{ Ano } & \multirow{2}{*}{$\begin{array}{l}\mathrm{N}^{\circ} \text { de } \\
\text { artigos por } \\
\text { década }\end{array}$} & \multirow{2}{*}{$\begin{array}{l}\mathrm{N}^{\circ} \text { de } \\
\text { artigos } \\
\text { por } \\
\text { ano }\end{array}$} & \multicolumn{16}{|c|}{ Número de artigos por revista } \\
\hline & & & 妾 & 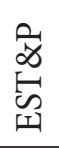 & 덤 & 点 & 娄 & $\begin{array}{l}\text { 壵 } \\
\text { 童 }\end{array}$ & $\begin{array}{l}\circlearrowright \\
Z \\
\text { Z }\end{array}$ & $\begin{array}{l}\vec{A} \\
\text { 至 }\end{array}$ & 峲 & 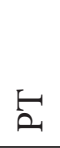 & 펑 & 㞬 & $\begin{array}{l}\text { 罂 } \\
\text { 它 }\end{array}$ & 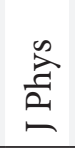 & 코 & 㿠 \\
\hline 2000 & \multirow{11}{*}{35} & 2 & & & 2 & & & & & & & & & & & & & \\
\hline 2001 & & 3 & & & & & 1 & 1 & & & & & & & 1 & & & \\
\hline 2002 & & 4 & & & & & 2 & & 1 & & & & & & 1 & & & \\
\hline 2003 & & 1 & & & & & & & & & & & 1 & & & & & \\
\hline 2004 & & 1 & & & & & & & & & & & 1 & & & & & \\
\hline 2005 & & 1 & & & & & & & & & & & & 1 & & & & \\
\hline 2006 & & 2 & & & & & & & & & & 1 & 1 & & & & & \\
\hline 2007 & & 5 & & & & & & 2 & & & & & 1 & 1 & 1 & & & \\
\hline 2008 & & 5 & & & & & 2 & 1 & 1 & & & & 1 & & & & & \\
\hline 2009 & & 5 & & & & & 2 & 1 & & & & & 1 & & & & & 1 \\
\hline 2010 & & 6 & 3 & & & 1 & & & & & 1 & 1 & & & & & & \\
\hline 2011 & \multirow{8}{*}{60} & 8 & 3 & & & 1 & 2 & & & & & & 1 & 1 & & & & \\
\hline 2012 & & 6 & 3 & & & & 1 & 1 & & & & & & & 1 & & & \\
\hline 2013 & & 5 & 1 & & & & & 3 & & & & & & & & & 1 & \\
\hline 2014 & & 3 & 1 & & & 1 & & 1 & & & & & & & & & & \\
\hline 2015 & & 13 & 9 & 1 & & & & & & 1 & & & 1 & & 1 & & & \\
\hline 2016 & & 4 & 2 & & & 1 & & & & & & & & & 1 & & & \\
\hline 2017 & & 13 & 8 & & & 3 & & & & & & & & & 1 & 1 & & \\
\hline 2018 & & 8 & 1 & & & 2 & 1 & & & & & & 1 & & 1 & & & 2 \\
\hline Total & 95 & 95 & 31 & 1 & 2 & 9 & 11 & 10 & 2 & 1 & 1 & 2 & 9 & 3 & 8 & 1 & 1 & 3 \\
\hline
\end{tabular}

De acordo com os dados contidos na Tabela 1, percebe-se a diversidade de revistas que abrem espaço para publicar artigos sobre a temática do ensino de $\mathrm{MQ}$, o que significa um importante apoio a área. Destaca-se a Physical Review Special Topics, que apresenta um grande número de artigos. Deve-se levar em consideração que o 
tema Física Quântica, em essência, é complexo. Muitos artigos destinam-se somente a discutir questões conceituais e teóricas sem efetuar propostas didáticas; outros analisam respostas dos estudantes; outros relatam implementações didáticas, etc.

Nesses moldes, apenas 9 estudos realizados no contexto de um componente curricular foram identificados. $O$ fato de não haver muitos artigos que fazem uma proposta "completa" traduz, na verdade, uma questão editorial - diferentes revistas tradicionalmente são mais comprometidas com diferentes partes do processo educacional. Estes estudos $(n=86)$ sinalizam a ascensão desta área, ensino de $\mathrm{MQ}$, vislumbrando sua melhoria e aperfeiçoamento nos processos de ensino-aprendizagem.

As informações contidas na Tabela 1 permitem traçar um perfil quantitativo das publicações em revistas, no que se refere à temática de pesquisa em Ensino de Física sobre tópicos da MQ. Tais informações podem ser úteis, sobretudo, para pesquisadores iniciantes, quando se busca por trabalhos de referência focados nessa área. Ao avaliar o panorama geral, pode-se observar de imediato, conforme mostrado no Figura 3, o aumento substancial do número de pesquisas referentes a investigações sobre o ensino de MQ ao longo dos anos.

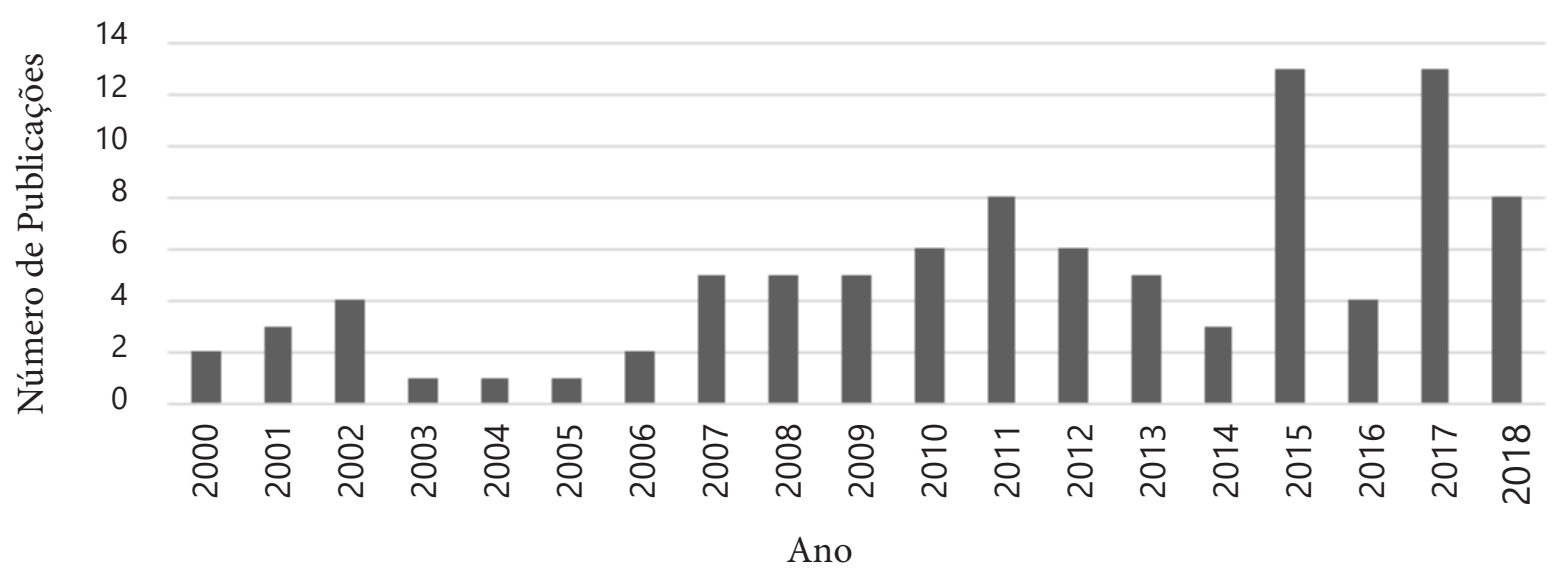

Figura 3. Distribuição, por ano, do número de publicações selecionadas ( $n=95$ artigos)

Esse aumento pode ser justificado pela crescente preocupação dos pesquisadores sobre o tema, conforme tem sido documentado em vasta literatura (Didiş et al., 2010; Greca \& Freire Jr, 2014; Johnston et al., 1998; Krijtenburg-Lewerissa et al., 2017; Pospiech \& Schöne, 2014; Rocha et al., 2010; Styer, 1996; Zollman et al., 2002).

Por outra parte, argumentos são apresentados para explicar por que a abordagem usual para o ensino da MQ introdutória parece não conseguir uma compreensão conceitual. Sabe-se que algumas das dificuldades são de origem dos próprios fundamentos quânticos, como a noção de probabilidade, incerteza e superposição. Esses conceitos são essenciais para a compreensão da $M Q$, porém não triviais. São contra intuitivos e geram conflitos com a visão determinista da Física Clássica que é familiar para a maioria dos estudantes (Müller \& Wiesner, 2002; Santos, 2012). Essa questão é apenas uma entre as várias que constituem desafios enfrentados no ensino da MQ.

Outras dificuldades no processo de ensino-aprendizagem a respeito de conteúdos 
de MQ podem ser listadas a partir das revisões de literatura mencionadas (Cuesta, 2018; Greca \& Moreira, 2001; Krijtenburg-Lewerissa et al., 2017; Pantoja et al., 2011; Pereira \& Ostermann, 2009; Rocha et al., 2018): 1) associar os novos conceitos com experiências cotidianas, parecendo que esses conceitos são aprendidos fora de contexto e uma série de concepções erradas é propagada por estudantes, professores e textos; 2) o conhecimento dos estudantes sobre MQ ser muito superficial, não passando de uma coleção de fatos isolados, úteis para a aprovação nos cursos; 3) pouca clareza sobre os limites de validade da MQ e da Física Clássica; 5) os livros didáticos introdutórios contribuem para a formação de uma visão equivocada dos fenômenos; 6) restrição do ensino de MQ apenas aos períodos finais dos cursos de física; 7) aulas tradicionais nas quais os conteúdos de MQ são apresentados às vezes em forma axiomática, às vezes em forma "quase-histórica" que gera uma espécie de barreira para a compreensão; 8) os tópicos tratados ainda são poucos (estabilidade do átomo, dualidade onda-partícula, princípio de incerteza, quantização, fótons e elétrons) deixando de lado questões importantes como superposição de estados ou o problema da medida. Essas dificuldades são apenas algumas entre as várias que constituem os desafios enfrentados.

Dos principais obstáculos observados na literatura ao ensino de MQ, destacamse: 1) a linguagem utilizada nos materiais disponíveis, a qual nem sempre contribui para facilitar o entendimento dos conceitos; 2) a falta de tempo e de condições para que os professores realizem a seleção dos assuntos a serem abordados; 3) a falta de capacitação; 4) a necessidade de novas metodologias que facilitem a transição do pensamento de uma física intuitiva e quantificável para uma abstrata e probabilística; 5) a dificuldade de contemplar outros conteúdos em um currículo já tão extenso - somente para citar alguns fatores (Carvalho Neto et al., 2009; Chaves, 2010; Fanaro et al., 2007; Ferreira, 2013; Greca \& Moreira, 2001; Machado \& Nardi, 2006; Oliveira et al., 2007; Paulo \& Moreira, 2011; Silva \& Almeida, 2011). Dos obstáculos, resulta-se uma obstrução ao processo de ensino-aprendizagem de Física (Dominguini, 2012; Pereira \& Aguiar, 2006; Pereira \& Schumacher, 2013).

Todas essas questões fomenta o aumento do quantitativo de pesquisas na área. $\mathrm{O}$ ponto principal é a perspectiva de como melhorar o ensino da MQ, pois as dificuldades são comuns e aceitáveis, mas precisam ser sanadas. Nesse sentido, há propostas de inclusão de tópicos específicos, mudança de enfoque didático, alterações curriculares, inclusão de recursos computacionais, elaboração de unidades didáticas e divulgação de materiais desenvolvidos para o ensino objetivando criar condições para que os estudantes compreendam os fenômenos e conceitos fundamentais da teoria (Bao et al., 1996; Cuesta, 2018; Greca \& Moreira, 2001; Meltzer \& Thornton, 2012; Pantoja et al., 2011; Pereira \& Ostermann, 2009; Rocha, et al., 2018).

Essa visão de aspectos em geral, a priori, permite-nos afirmar a existência da necessidade de aproximação dos resultados de pesquisas aos processos pedagógicos e de ensino-aprendizagem da MQ nos cursos de graduação em Física. Podemos inferir que não é suficiente ações isoladas, pois, a longo prazo, pode-se prevalecer os métodos 
tradicionais de ensino, seja por motivos políticos e econômicos da própria educação, seja por problemas na formação do professor (Barros \& Freire Jr., 2011; Carvalho, 2017; Marandino, 2003). Outra razão para não se efetivar essas mudanças curriculares pode ser atribuída ao fato que o currículo não é, simplesmente, um projeto que diz respeito somente a professores e a estudantes, mas que abrange vários intervenientes que, direta ou indiretamente, participam na sociedade do conhecimento ou na sociedade de aprendizagem (Pacheco, 2001). Essas questões são pertinentes, mas não serão discutidas neste artigo por não ser o foco do mesmo.

\section{Componente curricular de MQ na graduação em Física}

Da avaliação crítica dos estudos que compõe o objetivo desta revisão $(n=9)$, apresenta-se a caracterização do perfil dos cursos de MQ na graduação em Física com observância nas atuais tendências curriculares, segundo a identificação de 10 dimensões, a saber: título do estudo, país de origem, autor, ano de desenvolvimento, objetivos, instrumentos, participantes (Figura 4); conteúdo ministrado, bases teóricometodológicas e principais resultados (Figura 5). Admitindo essas categorias, analisamse os estudos selecionados identificando os respectivos impactos sobre o processo de ensino e aprendizagem dos fenômenos quânticos. Inferimos que conhecer a forma que a MQ tem sido ministrada nos componentes curriculares pode apresentar indícios de como avançar na busca por melhorias nos processos formativos.

\begin{tabular}{|l|l|l|l|l|}
\hline Art & Título & $\begin{array}{l}\text { País } \\
\text { Autor(es) } \\
\text { Ano }\end{array}$ & Objetivo de Estudo & $\begin{array}{l}\text { Instrumento } \\
\text { Participantes }\end{array}$ \\
\hline A1 & $\begin{array}{l}\text { Student } \\
\text { understanding } \\
\text { of quantum } \\
\text { mechanics }\end{array}$ & $\begin{array}{l}\text { USA } \\
\text { Singh } \\
2001\end{array}$ & $\begin{array}{l}\text { Identificar as dificuldades } \\
\text { dos estudantes no estudo } \\
\text { da MQ e analisar se estão } \\
\text { correlacionadas com o } \\
\text { método de ensino }\end{array}$ & $\begin{array}{l}\text { Teste escrito } \\
\text { Entrevista } \\
89 \text { estudantes de 6 } \\
\text { universidades }\end{array}$ \\
\hline A2 & $\begin{array}{l}\text { Uma Proposta } \\
\text { para o ensino de } \\
\text { Mecânica Quântica }\end{array}$ & $\begin{array}{l}\text { Greca, } \\
\text { Moreira e } \\
\text { Herscovitz } \\
2001\end{array}$ & $\begin{array}{l}\text { Ensinar conceitos } \\
\text { quânticos de } \\
\text { forma conceitual- } \\
\text { fenomenológica para } \\
\text { familiarizar o estudante } \\
\text { com a "percepção" } \\
\text { quântica }\end{array}$ & $\begin{array}{l}\text { Pré e pós-teste } \\
\text { 25 estudantes } \\
\text { Carga horária de 24 h/ } \\
\text { aula }\end{array}$ \\
\hline A3 & $\begin{array}{l}\text { Teaching quantum } \\
\text { mechanics on an } \\
\text { introductory level }\end{array}$ & $\begin{array}{l}\text { DE } \\
\text { Müller e } \\
\text { Wiesner } \\
2002\end{array}$ & $\begin{array}{l}\text { Apresentar um curso } \\
\text { introdutório de MQ } \\
\text { centrado nas diferenças } \\
\text { com a mecânica clássica }\end{array}$ & $\begin{array}{l}\text { Questionário } \\
\text { Entrevistas } \\
60 \text { estudantes } \\
\text { Carga horária de 30h/aula }\end{array}$ \\
\hline
\end{tabular}

Figura 4. Sinopse de estudos relativos aos cursos de Mecânica Quântica (MQ) (Parte I) (continua) 


\begin{tabular}{|c|c|c|c|c|}
\hline Art & Título & $\begin{array}{l}\text { País } \\
\text { Autor(es) } \\
\text { Ano } \\
\end{array}$ & Objetivo de Estudo & $\begin{array}{l}\text { Instrumento } \\
\text { Participantes }\end{array}$ \\
\hline $\mathrm{A} 4$ & $\begin{array}{l}\text { Interpretações da } \\
\text { Teoria Quântica e } \\
\text { as concepções dos } \\
\text { estudantes do curso } \\
\text { de Física }\end{array}$ & $\begin{array}{l}\text { BR } \\
\text { Montenegro } \\
\text { e Pessoa Jr. } \\
2002\end{array}$ & $\begin{array}{l}\text { Verificar as } \\
\text { "interpretações" que } \\
\text { os estudantes adotam } \\
\text { quando estudam MQ }\end{array}$ & $\begin{array}{l}\text { Questionário } \\
\text { Entrevistas } \\
8 \text { turmas, total de } 131 \\
\text { estudantes }\end{array}$ \\
\hline A5 & $\begin{array}{l}\text { Graduate quantum } \\
\text { mechanics reform }\end{array}$ & $\begin{array}{l}\text { USA } \\
\text { Carr e } \\
\text { McKagan } \\
2009\end{array}$ & $\begin{array}{l}\text { Refletir sobre as técnicas } \\
\text { usualmente adotadas } \\
\text { nos cursos de MQ e } \\
\text { o progresso obtido a } \\
\text { partir de uma nova } \\
\text { proposta }\end{array}$ & $\begin{array}{l}\text { Questionário } \\
\text { Avaliações obrigatórias } \\
\text { discente-docente } \\
\text { Curso realizado } 3 \text { vezes }\end{array}$ \\
\hline A6 & $\begin{array}{l}\text { Teaching and } \\
\text { understanding } \\
\text { of quantum } \\
\text { interpretations in } \\
\text { modern physics } \\
\text { courses }\end{array}$ & $\begin{array}{l}\text { USA } \\
\text { Baily e } \\
\text { Finkelstein } \\
2010\end{array}$ & $\begin{array}{l}\text { Documentar } \\
\text { as variações } \\
\text { nas abordagens } \\
\text { instrucionais e examinar } \\
\text { os impactos sobre } \\
\text { as perspectivas dos } \\
\text { estudantes em relação à } \\
\text { física quântica }\end{array}$ & $\begin{array}{l}\text { Pré e pós-teste } \\
\text { Entrevistas } \\
75 \text { estudantes } \\
\text { Carga horária de } 28 \mathrm{~h} / \\
\text { aula } \\
\text { Duas aplicações }\end{array}$ \\
\hline A7 & $\begin{array}{l}\text { Learning and } \\
\text { retention of quantum } \\
\text { concepts with } \\
\text { different teaching } \\
\text { methods }\end{array}$ & $\begin{array}{l}\text { CAN } \\
\text { Deslauriers e } \\
\text { Wieman } \\
2011\end{array}$ & $\begin{array}{l}\text { Verificar o domínio } \\
\text { e a retenção da } \\
\text { compreensão da MQ } \\
\text { pelos estudantes }\end{array}$ & $\begin{array}{l}\text { Questionário } \\
60 \text { estudantes } \\
\text { Carga horária de } 40 \text { h/ } \\
\text { aula } \\
\text { Duas aplicações } \\
\end{array}$ \\
\hline A8 & $\begin{array}{l}\text { Improving students' } \\
\text { understanding } \\
\text { of quantum } \\
\text { measurement. I. } \\
\text { Investigation of } \\
\text { difficulties } \\
\end{array}$ & $\begin{array}{l}\text { USA } \\
\text { Zhu e } \\
\text { Singh } \\
2012\end{array}$ & $\begin{array}{l}\text { Descrever as } \\
\text { dificuldades de } \\
\text { compreensão das } \\
\text { medições quânticas }\end{array}$ & $\begin{array}{l}\text { Questionário } \\
\text { Entrevistas } \\
\text { Testes abertos/múltipla } \\
\text { escolha } \\
\text { Seis instituições } \\
\end{array}$ \\
\hline A9 & $\begin{array}{l}\text { The analysis of } \\
\text { analogy use in } \\
\text { the teaching of } \\
\text { introductory quantum } \\
\text { theory }\end{array}$ & $\begin{array}{l}\text { TR } \\
\text { Didis } \\
2015\end{array}$ & $\begin{array}{l}\text { Analisar analogias } \\
\text { utilizadas no ensino de } \\
\text { conceitos introdutórios } \\
\text { da teoria quântica }\end{array}$ & $\begin{array}{l}\text { Questionário } \\
\text { Entrevistas } \\
20 \text { estudantes } \\
\text { Carga horária de } 60 \text { h/ } \\
\text { aula }\end{array}$ \\
\hline
\end{tabular}

Figura 4. Sinopse de estudos relativos aos cursos de Mecânica Quântica (MQ) (Parte I) (continuação) 
Dos 9 estudos selecionados, segundo a estratégia estabelecida após a implementação dos critérios de exclusão, 4 foram realizados nos Estados Unidos, 2 no Brasil, 1 na Alemanha, 1 no Canadá, 1 na Turquia. Existem poucos estudos para uma análise voltada para cursos de graduação em Física e realizados no contexto de um componente curricular de MQ. Entretanto, em outros contextos esses números poderiam ser diferentes. Nos trabalhos anteriores de revisão da literatura, Ostermann e Moreira (2000), Greca e Moreira (2001), Pereira e Ostermann (2009), Pantoja et al., (2011) e Rocha et al., (2018), em sua totalidade, apresentam mais de 340 artigos sobre a introdução de física moderna e contemporânea e sobre o ensino de MQ atingindo cursos introdutórios (em nível médio e superior) publicados nas revistas mais importantes de Ensino de Física/Ciências do país e do exterior, desde 1970 até 2016, com crescimento nos últimos anos e expressivo interesse em pesquisas nesta área. Porém, apesar do aumento na quantidade de publicações nesta área, observa-se que a maioria dos artigos ainda se refere a bibliografias de consulta para professores. Há escassez de estudos relativos à formação inicial e continuada de professores, o que reflete no presente resultado dessa investigação específica.

Estes trabalhos (Figura 4), por simplificação, passam a ser nomeados com referências de A1 a A9 (as referências completas são listadas ao término deste trabalho).

\begin{tabular}{|c|c|c|c|}
\hline Art & Conteúdo ministrado & $\begin{array}{l}\text { es teórico- } \\
\text { odológicas }\end{array}$ & Principais resultados \\
\hline $\mathrm{A} 1$ & $\begin{array}{l}\text { - Formalismo básico da } \\
\text { MQ } \\
\text { - Medições Quânticas } \\
\text { - Interpretação de } \\
\text { Copenhague } \\
\text { - Operadores } \\
\text { - Estados estacionários } \\
\text { - Autoestados e a } \\
\text { dependência do tempo } \\
\text { - Valores esperados }\end{array}$ & $\begin{array}{l}\text { - É demarcado um } \\
\text { modelo de ensino } \\
\text { tradicional } \\
\text { - Recurso } \\
\text { didático: } \\
\text { Livro didático }\end{array}$ & $\begin{array}{l}\text { - A análise dos dados revela uma série de } \\
\text { equívocos conceituais comuns entre os } \\
\text { estudantes; } \\
\text { - As dificuldades observadas são sobre } \\
\text { o formalismo matemático, significância } \\
\text { dos autoestados, valores esperados e sua } \\
\text { dependência do tempo, processo de medida; } \\
\text { - As dificuldades detectadas são atribuídas } \\
\text { a: 1) falta de conhecimento conceitual; } 2 \text { ) } \\
\text { conceito memorizado, mas interpretado } \\
\text { erroneamente; } 3 \text { ) conhecimento interpretado } \\
\text { no nível básico; mas não pode ser usado para } \\
\text { fazer inferências em situações específicas. }\end{array}$ \\
\hline
\end{tabular}

Figura 5. Sinopse de estudos relativos aos cursos de Mecânica Quântica (MQ) (Parte II) (continua) 


\begin{tabular}{|c|c|c|c|}
\hline Art & Conteúdo ministrado & $\begin{array}{l}\text { Bases teórico- } \\
\text { metodológicas }\end{array}$ & Principais resultados \\
\hline $\mathrm{A} 2$ & $\begin{array}{l}\text { - Computação quântica } \\
\text { - Sistemas quânticos } \\
\text { - Superposição de } \\
\text { estados } \\
\text { - Dualidade onda- } \\
\text { partícula } \\
\text { - Princípio de Incerteza } \\
\text { - Probabilidade no } \\
\text { processo de medida } \\
\text { - Problema da medida } \\
\text { - Átomo de hidrogênio } \\
\text { - Tunelamento } \\
\text { - Laser e técnicas de } \\
\text { resfriamento } \\
\text { - Interpretação de Von } \\
\text { Neumann }\end{array}$ & $\begin{array}{l}\text {-É adotada a teoria dos } \\
\text { modelos mentais de } \\
\text { Johnson-Laird } \\
\text { - É realizada } \\
\text { uma abordagem } \\
\text { fenomenológica- } \\
\text { conceitual } \\
\text { - Trabalho em pequenos } \\
\text { grupos com auxílio do } \\
\text { professor } \\
\text { - Recurso didático: } \\
\text { Texto específico escrito } \\
\text { pelos autores }\end{array}$ & $\begin{array}{l}\text { - A análise dos dados revela que a } \\
\text { abordagem desenvolvida promoveu } \\
\text { compreensão de fenômenos } \\
\text { microscópicos, com } 84 \% \text { de êxito; } \\
\text { - Abordar o desenvolvimento da } \\
\text { teoria e inovações tecnológicas foi um } \\
\text { aspecto motivador para os estudantes; } \\
\text { - O estudo sugere a relevância de } \\
\text { utilizar um mínimo de ferramentas } \\
\text { matemáticas e a dimensão histórico- } \\
\text { epistemológica sem recair em } \\
\text { simplificações exageradas. }\end{array}$ \\
\hline A3 & $\begin{array}{l}\text { Parte } 1 \text { (Fótons) } \\
\text { - Efeito fotoelétrico } \\
\text { - Propriedades } \\
\text { dinâmicas } \\
\text { (Interferômetro Mach- } \\
\text { Zehnder) } \\
\text { - Interpretação } \\
\text { probabilística de Born } \\
\text { Parte } 2 \text { (Elétrons) } \\
\text { - Difração do elétron } \\
\text { (Experimento Double- } \\
\text { Slit) } \\
\text { - Problema da medida } \\
\text { - Gato de Schrödinger } \\
\text { - Relação de incerteza }\end{array}$ & $\begin{array}{l}\text { - É priorizada discussão } \\
\text { conceitual } \\
\text { - O curso é dividido } \\
\text { em dois momentos: } 1^{\circ} \\
\text { explora o raciocínio } \\
\text { argumentativo } \\
\text { (fundamentos quânticos } \\
\text { com uso de simulações } \\
\text { feitas na sala e também } \\
\text { em casa); } 2^{\circ} \text { introduz o } \\
\text { formalismo da MQ. } \\
\text { - Recurso didático: } \\
\text { Texto específico escrito } \\
\text { pelos autores }\end{array}$ & $\begin{array}{l}\text { - A discussão dos experimentos da } \\
\text { dupla fenda e do interferômetro de } \\
\text { Mach-Zehnder através de simulações } \\
\text { auxiliam na compreensão de aspectos } \\
\text { genuinamente quânticos, superando } \\
\text { concepções alternativas próprias de } \\
\text { abordagens tradicionais; } \\
\text { - O estudo sugere o desenvolvimento } \\
\text { de novos recursos, como o uso de } \\
\text { multimídia, simulações e hipertexto } \\
\text { que incluam resultados atuais da } \\
\text { pesquisa em MQ como a informação } \\
\text { quântica, discussões sobre o paradoxo } \\
\text { EPR e as desigualdades de Bell; } \\
\text { - É apresentado um projeto em } \\
\text { desenvolvimento de formação de } \\
\text { professores em MQ via Web, no qual } \\
\text { exploram tais recursos e conteúdo. }\end{array}$ \\
\hline
\end{tabular}

Figura 5. Sinopse de estudos relativos aos cursos de Mecânica Quântica (MQ) (Parte II) (continua) 


\begin{tabular}{|c|c|c|c|}
\hline Art & Conteúdo ministrado & $\begin{array}{l}\text { Bases teórico- } \\
\text { metodológicas }\end{array}$ & Principais resultados \\
\hline A 4 & $\begin{array}{l}\text { - Interpretações oficiais da } \\
\text { MQ } \\
\text { - Experimento da fenda } \\
\text { dupla } \\
\text { - Princípio da incerteza } \\
\text { - Interpretação do estado } \\
\text { quântico } \\
\text { - Retrodição } \\
\text { - Postulado da projeção }\end{array}$ & $\begin{array}{l}\text { - É demarcado um } \\
\text { modelo de ensino } \\
\text { tradicional } \\
\text { - Recurso didático: } \\
\text { Livro didático }\end{array}$ & $\begin{array}{l}\text { - É constatado que os estudantes } \\
\text { utilizam diferentes interpretações } \\
\text { "privadas" a depender do problema } \\
\text { proposto para análise e que o } \\
\text { excessivo uso de cálculos com pouca } \\
\text { ênfase conceitual é fonte de várias } \\
\text { dificuldades; } \\
\text { - Os autores consideram haver } \\
\text { uma negligência no estudo do } \\
\text { processo de medida nos cursos } \\
\text { de MQ (questões conceituais e } \\
\text { interpretativas); }\end{array}$ \\
\hline A5 & $\begin{array}{l}\text { O curso é dividido em } \\
\text { quatro períodos: } \\
\text { - I: Formulação da } \\
\text { equação de Schrödinger, } \\
\text { contribuições de } \\
\text { Schrödinger, Born, Dirac, } \\
\text { von Neumann e outros } \\
\text { incluindo mecânica } \\
\text { das ondas, formulação } \\
\text { matricial e dinâmica } \\
\text { elementar } \\
\text { - II: Interpretações } \\
\text { - III: Teorema de Bell, } \\
\text { experimentos de Aspect e } \\
\text { as Desigualdades de Bell } \\
\text { - IV: Processamento de } \\
\text { informações quânticas e } \\
\text { entrelaçamento }\end{array}$ & $\begin{array}{l}\text { - Ensino tradicional } \\
\text { versus abordagem } \\
\text { conceitual-contextual } \\
\text { - Trabalho em grupo e } \\
\text { discussões abertas } \\
\\
\text { Recurso didático: } \\
\text { Diferentes livros } \\
\text { didáticos (Sakurai que } \\
\text { cobre os períodos I e } \\
\text { II, Le Bellac e Gottfried } \\
\text { e Yan que perpassa os } \\
\text { períodos de I a IV) e } \\
\text { notas de aula. }\end{array}$ & $\begin{array}{l}\text { - O ensino interativo e o trabalho } \\
\text { em grupo aumentam gradualmente } \\
\text { os rendimentos dos estudantes } \\
\text { em comparação com o ensino } \\
\text { tradicional e auxilia na compreensão } \\
\text { conceitual e na resolução de } \\
\text { problemas; } \\
\text { - É sugerido (re)construção dos } \\
\text { cursos com reflexão em quatro áreas } \\
\text { principais: seleção de conteúdo, } \\
\text { livros didáticos, métodos de ensino } \\
\text { e ferramentas de avaliação. }\end{array}$ \\
\hline
\end{tabular}

Figura 5. Sinopse de estudos relativos aos cursos de Mecânica Quântica (MQ) (Parte II) (continua) 


\begin{tabular}{|c|c|c|c|}
\hline Art & Conteúdo ministrado & $\begin{array}{l}\text { Bases teórico- } \\
\text { metodológicas }\end{array}$ & Principais resultados \\
\hline A6 & $\begin{array}{l}\text { - Introdução à Física } \\
\text { Quântica } \\
\text { - Efeito Fotoelétrico, } \\
\text { Fótons } \\
\text { - Espectro Atômico, } \\
\text { Modelo de Bohr } \\
\text { - Ondas de De Broglie } \\
\text { - Modelo Atômico } \\
\text { - Ondas de matéria/ } \\
\text { Interferência } \\
\text { - Funções de onda de } \\
\text { Schrödinger } \\
\text { - Energia Potencial } \\
\text { - Tunelando e decaimento } \\
\text { - Átomo de hidrogênio } \\
\text { - Átomos, tabela periódica, } \\
\text { sólidos }\end{array}$ & 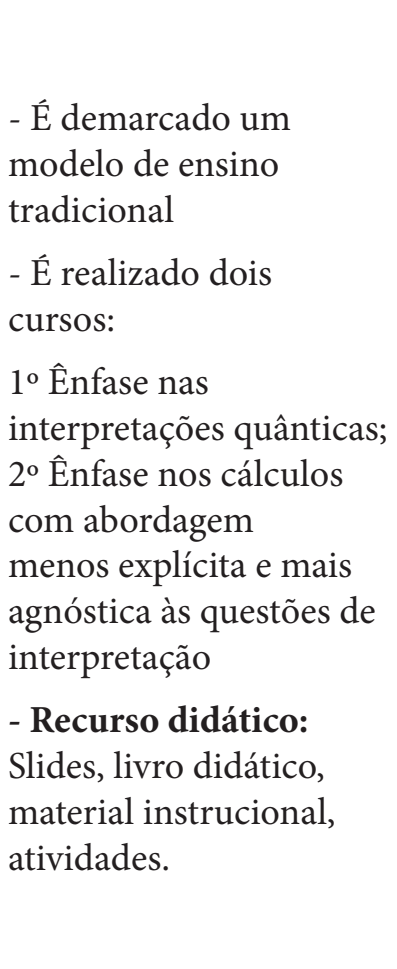 & $\begin{array}{l}\text { - A análise dos dados revela que } \\
\text { estudantes são mais propensos a } \\
\text { preferir uma interpretação realista } \\
\text { da MQ quando submetidos a uma } \\
\text { abordagem na qual os instrutores } \\
\text { são menos explícitos na abordagem } \\
\text { ontológica junto aos estudantes; } \\
\text { - Os autores chamam a atenção para } \\
\text { o fato que os estudantes são capazes } \\
\text { de aplicar ferramentas matemáticas } \\
\text { sem uma correspondente } \\
\text { compreensão conceitual o que } \\
\text { prejudica a aprendizagem. Logo, } \\
\text { precisa ser incentivada. }\end{array}$ \\
\hline A7 & $\begin{array}{l}\text { - Efeito fotoelétrico } \\
\text { - Espectro Atômico, } \\
\text { Modelo de Bohr } \\
\text { - Ondas de De Broglie } \\
\text { - Modelo Atômico } \\
\text { - Ondas de matéria/ } \\
\text { Interferência } \\
\text { - Funções de onda de } \\
\text { Schrödinger } \\
\text { - Energia Potencial } \\
\text { - Tunelamento e } \\
\text { decaimento } \\
\text { - Átomo de hidrogênio } \\
\text { - Átomos multieletrônicos, } \\
\text { tabela periódica, sólidos }\end{array}$ & $\begin{array}{l}\text { - Ensino tradicional } \\
\text { versus abordagem } \\
\text { fenomenológica } \\
\text { - Dois cursos são } \\
\text { aplicados. No curso } 2 \\
\text { buscou incluir discussão } \\
\text { fenomenológica } \\
\text { envolvendo conceitos e } \\
\text { cálculos } \\
\text { - Recurso didático: } \\
\text { Curso } 1 \text { - livro didático } \\
\text { Curso } 2 \text { - simulações } \\
\text { PhET, leitura, discussão, } \\
\text { atividades em grupo e } \\
\text { notas de aula. }\end{array}$ & $\begin{array}{l}\text { - Para os autores, os métodos de } \\
\text { ensino têm impacto substancial } \\
\text { na aprendizagem e retenção dos } \\
\text { conceitos, mas independente da } \\
\text { abordagem os estudantes estão } \\
\text { mais propensos a recordar de } \\
\text { conhecimentos factuais, os quais } \\
\text { serão esquecidos rapidamente. }\end{array}$ \\
\hline
\end{tabular}

Figura 5. Sinopse de estudos relativos aos cursos de Mecânica Quântica (MQ) (Parte II) (continua) 


\begin{tabular}{|c|c|c|c|}
\hline Art & Conteúdo ministrado & $\begin{array}{l}\text { Bases teórico- } \\
\text { metodológicas }\end{array}$ & Principais resultados \\
\hline A8 & $\begin{array}{l}\text { - Interpretação da MQ } \\
\text { - Formalismo de Dirac } \\
\text { - Problema da medição } \\
\text { - Observáveis } \\
\text { - Probabilidade de } \\
\text { obter autovalores, } \\
\text { estados estacionários e } \\
\text { autoestados }\end{array}$ & $\begin{array}{l}\text { - É demarcado o ensino } \\
\text { tradicional } \\
\text { - Recurso didático: } \\
\text { Livro didático e } \\
\text { atividades propostas. }\end{array}$ & $\begin{array}{l}\text { - Dentre os resultados destaca-se a } \\
\text { dificuldade dos estudantes em: } \\
\text { a)perceber a diferença entre a } \\
\text { probabilidade de medir cada valor } \\
\text { possível de um observável e o valor } \\
\text { esperado daquele observável, num } \\
\text { dado estado; b)transferência não } \\
\text { apropriada entre conceito clássico } \\
\text { de probabilidade para o conceito } \\
\text { de probabilidade quântica; c) } \\
\text { desconforto dos estudantes ao } \\
\text { descreverem a evolução no tempo } \\
\text { de um sistema quântico em termos } \\
\text { do desenvolvimento da função de } \\
\text { onda no tempo; } \\
\text { - A pesquisa mostrou que os } \\
\text { estudantes resistem ao significado } \\
\text { da medição, em termos do que } \\
\text { acontece com o estado do sistema } \\
\text { após a medição de um observável. }\end{array}$ \\
\hline A9 & $\begin{array}{l}\text { - Radiação do corpo } \\
\text { negro } \\
\text { - Efeito fotoelétrico } \\
\text { - Dualidade onda- } \\
\text { partícula } \\
\text { - Átomo de Hidrogênio } \\
\text { - Oscilador harmônico } \\
\text { - Tunelamento } \\
\text { - Modelos atômicos } \\
\text { - Experimento de } \\
\text { Rutherford } \\
\text { - Quantização do momento } \\
\text { angular } \\
\text { - Efeito Zeeman } \\
\text { - Radioatividade e } \\
\text { decaimento }\end{array}$ & $\begin{array}{l}\text { - Discussão conceitual } \\
\text { baseada em Shulman } \\
\text { (1986) } \\
\text { - Uso de analogias para } \\
\text { esclarecimento dos } \\
\text { conceitos via modelo } \\
\text { Teaching-With-Analogies } \\
\text { de Glynn (TWA) } \\
\text { - Recurso didático: } \\
\text { Analogias, } \\
\text { dramatizações, história e } \\
\text { atividades em grupo. }\end{array}$ & $\begin{array}{l}\text { - Os contextos de aprendizagem e } \\
\text { compreensão de novos conceitos } \\
\text { podem ser facilitados com o uso das } \\
\text { analogias; } \\
\text { - Os autores argumentam que } \\
\text { embora os conceitos da MQ sejam } \\
\text { abstratos e contra intuitivos, } \\
\text { as analogias podem ajudar no } \\
\text { desenvolvimento de concepções } \\
\text { quânticas ou na construção de } \\
\text { novos desenhos instrucionais. }\end{array}$ \\
\hline
\end{tabular}

Figura 5. Sinopse de estudos relativos aos cursos de Mecânica Quântica (MQ) (Parte II) (continuação) 
A fim de facilitar a discussão que se segue a respeito desses artigos, uma síntese dos estudos - focada nos objetivos, conteúdo ministrado, bases teórico-metodológica e resultados obtidos - será apresentada com vistas a trazer à tona as principais informações que tais pesquisas têm fornecido sobre propostas curriculares para o ensino de MQ com a intenção de contribuir com os pesquisadores que atuam nessa área.

Em geral, os objetivos dos estudos estabelecidos configuram duas linhas de pesquisa: a primeira investiga as dificuldades dos estudantes no processo de ensino e aprendizagem; e a segunda contempla bases teórico-metodológicas investindo esforços na compreensão conceitual sobre os fenômenos quânticos. Em consonância, a análise detalhada mostra que a abordagem da MQ nos cursos investigados contempla o ensino tradicional (A1, A4, A6, A8 - primeira linha), abordagem com propostas didáticas inovadoras (A2, A3, A9 - segunda linha) e os que buscam estabelecer comparações entre o ensino tradicional e o ensino com propostas didáticas inovadoras (A5 e A7).

Salientamos que chamamos de ensino tradicional aquele em que, entre outros aspectos, privilegia a transmissão de conteúdo, aulas expositivas, com pouca atividade/ participação dos alunos e excesso do cálculo matemático sem o adequado tratamento teórico (Moreira, 2018). Enquanto, os que buscam novas propostas são aqueles que não se limitam ao ensino e apresentação de conteúdo tal como postos em livros didáticos e com aulas unicamente expositivas, mas que os pesquisadores optam por incluir outras estratégias para tratar dos conceitos e fenômenos quânticos. A mediação do professor deve ajudar a aplicar conceitos e procedimentos físicos em situações que lhes façam sentido, em uma perspectiva contemporânea, conceitual, epistemológica e de transposição didática, o que segundo Moreira (2018) não exclui que em determinados momentos o professor faça breves apresentações e explicações mais expositivas.

O programa desses cursos concentra-se em conteúdo da Antiga MQ - 6 estudos (A1, A3, A4, A6, A7, A9), 2 estudos priorizam a MQ Moderna (A2 e A8) e 1 estudo mescla os conteúdos (A5). Consequentemente, as interpretações da MQ explicitamente adotadas nas propostas (A1, A2, A3, A4, A5, A6, A8) concentram-se nas ditas "interpretações oficiais da MQ", tais como ondulatória (realista), corpuscular (realista), dualista realista, dualista positivista - que são 4 grandes grupos das quais se derivam várias outras interpretações (Pessoa Jr., 2003).

Em virtude dos objetivos definidos e do programa dos componentes curriculares, observam-se as diferentes percepções dos autores sobre os aspectos metodológicos que podem colaborar para o processo de ensino-aprendizagem. Esses aspectos tornamse determinantes para as escolhas pedagógicas. No entanto, foi notado que a maioria dos trabalhos não explicitam os referenciais pedagógicos que embasam a investigação feita. Não promove uma descrição empírica do contexto educacional. Ainda que fiquem demarcados o conteúdo, os objetivos e os recursos didáticos, os estudos carecem de informações quanto às bases teórico-metodológicas adotadas. Por exemplo, em termos de teorias de aprendizagem, apenas um estudo explicita em sua fundamentação teórica, a saber: A2 (Teoria dos modelos mentais de Johnson-Laird). 
Semelhantemente, Carvalho Neto (2016) em revisão de literatura, tomando por base artigos publicados em periódicos do Brasil e do exterior sobre a teoria quântica do processo de medida (ou tópicos ligados à medição quântica) categoriza: 1) propostas didáticas e/ou relatos de experiências didáticas; 2 ) discussões conceituais-interpretativas da MQ; 3) abordagem experimental. O autor constata que a discussão sobre a teoria quântica do processo de medida é ainda escassa, observando-se que tópicos específicos (ainda que essenciais) ligados ao processo de medida apareceram em vários deles, mas não o suficiente para caracterizar um estudo sobre a teoria quântica do processo de medida em sentido amplo. Assim como verificamos, Carvalho Neto relata que uma parte razoável dos trabalhos investigados não explicitam os referenciais pedagógicos que embasam a investigação feita, do ponto de vista do ensino-aprendizagem, nem explicitam suas escolhas epistemológicas.

Essas ausências de informações podem representar limitações na compreensão das práticas, bem como a respeito de características presentes no processo de ensino que podem ser úteis a reaplicações dos cursos propostos. Isso é um aspecto negativo dos artigos dado que, uma vez que se busca compreender os processos didáticos, seus avanços e dificuldades, a ausência de tais aspectos metodológicos se tornam barreiras a reaplicação. Assim sendo, os processos didáticos foram descritos admitindo essas limitações.

A respeito das bases teórico-metodológicas e recursos didáticos, é observado uma diversidade de opções, não excludentes entre si. Os pesquisadores autores dos artigos (A2, A5, A7 e A9) buscam instrumentos que proporcionem uma interação professoraluno ao expor fatos de forma ilustrativa, podendo suscitar a fala dos discentes sobre seus conhecimentos prévios dos conceitos de MQ e auxiliar na discussão dos fenômenos quânticos, tornando-os mais compreensíveis. Em termos de categorização destacamos: o uso de multimídia ${ }^{2}$; analogias; história da ciência; considerações das concepções prévias dos estudantes; incentivo a participação dos estudantes; uso do livro didático, sejam os convencionalmente adotados ou os mais recentes que apresentaram um grau de inovação e contextualização; uso de textos específicos elaborados pelos pesquisadores e atividades adequadas às respectivas propostas didáticas. Se percebe avanços no sentido de aproximar do ensino de MQ novas metodologias.

Em relação ao tempo de intervenção, as pesquisas, embora configuradas para cursos de um semestre, a carga horária e o número de estudantes envolvidos, foram muito variadas e são susceptíveis a cada contexto. Os estudos A2, A3, A4 e A9 apresentam dados de uma única turma; os estudos A1 e A8 avaliaram o componente MQ em 6 instituições distintas que seguiam a mesma estrutura de conteúdo e estratégia de ensino; os estudos A6 e A7 apresentam dados de duas aplicações e houve ainda o estudo A5 com duração de 1 ano. Como já fora ressaltado por Teixeira et al., (2012b, p. 26), numa

2 De acordo com Pretto (2013), é a junção de inúmeras possibilidades de produção e a incorporação de todos os meios da expressão e da comunicação, incluindo a simulação computacional que se trata da adoção de um aplicativo - a exemplo, os indexados no site Phet - que consiga representar um fenômeno quântico. 
revisão sistemática da literatura sobre o uso didático de História e Filosofia da Ciência no Ensino de Física: "Embora não exista uma relação entre tempo de intervenção e qualidade da pesquisa, pode-se afirmar que quanto maior o tempo de intervenção maiores as possibilidades da produção de efeitos a serem investigados".

Ainda, sobre a avaliação de cada estudo, observa-se uma predominância de trabalhos qualitativos. De acordo com Greca e Santos (2020) e Teixeira, Greca e Freire (2012b), no cenário da América Latina muitas pesquisas se enquadram dentro do amplo leque de metodologias qualitativas, incluindo os processos de interpretação de resultados, mas no cenário internacional, já há um certo equilíbrio entre métodos quali. e quanti. (Teixeira et al., 2012a). Nesta área, no entanto, esse equilíbrio não se observa. De forma coerente com o tipo de metodologia privilegiada, os instrumentos de coleta mais usados foram os questionários, a observação, as atividades e as entrevistas. $\mathrm{Na}$ maioria dos casos, os autores foram responsáveis pela elaboração da sequência didática, implementação, coleta e análise de dados.

Esse tipo de delineamento metodológico, o qual o pesquisador é também o professor aplicador da proposta, tem gerado controvérsias relacionadas com a possível interferência nos resultados das pesquisas, especialmente quando se leva em consideração as crenças dos professores acerca da ciência e das práticas em sala de aula (André, 2001; Villani \& Guridi, 2008). Portanto, a observação dos resultados destas pesquisas precisa ser feita à luz desta aferição.

Como instrumentos de avaliação das propostas, os pesquisadores utilizaram questionários, avaliação tradicional, atividades e entrevistas aplicados durante e/ou ao término da prática pedagógica. Esses instrumentos são utilizados como verificadores de concepções conceituais e causas subjacentes das dificuldades dos estudantes em sua aprendizagem. Em alguns casos, essas ferramentas de avaliação foram construídas considerando a literatura e experiências pessoais dos pesquisadores, em outros validados/ testados primeiramente pelos pares.

Em relação aos resultados dos estudos, que visam traçar caminhos para o sucesso no ensino de MQ e/ou apresentam algumas potencialidades em suas abordagens, destacamos entre as dificuldades listadas as discussões quanto às interpretações da MQ (ver A1, A2, A3, A4 e A6). Os estudantes adotavam ou se familiarizavam com determinada interpretação, sendo estas fontes de identificação de uma aprendizagem superficial à medida que os estudantes apresentam equívocos nas resoluções de suas atividades. Confusões ao interpretar os fenômenos quânticos aproximando-os do pensamento clássico, mudanças de interpretação dependendo do problema físico envolvido ou preferência por uma interpretação fazem parte do rol de dificuldades. Ocorre que o formalismo da teoria quântica é compatível com a maioria das interpretações que sugerem explicações divergentes, resultando em descrições diferentes da realidade.

Entre as propostas didáticas inovadoras (ver A2, A3, A5, A7 e A9), a maioria dos estudos afirma que não é suficiente fazer uso de diferentes estratégias e recursos metodológicos durante as aulas para superar as dificuldades que os estudantes apresentam 
no aprendizado da MQ, seja pelo caráter abstrato, contra intuitivo, falta de compreensão conceitual ou derivadas do uso excessivo do formalismo matemático. Reforçamos que a ênfase no uso de formalismo matemático não é necessariamente o maior problema, mas não atribuir significado físico a esse formalismo (quando for o caso). O simples fato de o formalismo ser enfatizado não é um problema em si, pois a Física Quântica é uma teoria altamente matematizada, e boa parte de seus desenvolvimentos foram realizados em trabalhos teóricos. Dessa forma, entendemos que o formalismo é parte estruturante da teoria, mas é fundamental significá-lo.

Nas conclusões das pesquisas, observam-se argumentos que incentivam: (A2) utilização de um mínimo de ferramentas matemáticas e a dimensão históricoepistemológica; (A3) uso de multimídia, simulações e hipertexto, além de incluir resultados atuais da pesquisa em MQ; (A6) investir na compreensão conceitual da MQ. Sem as quais o professor pode acabar por repetir o modelo tradicional de ensino com aulas predominantes expositivas e reprodução de conhecimentos prontos, inclusive utilizando-se dos mesmos instrumentos classificatórios de avaliação. A combinação entre as respectivas metodologias no ensino de MQ revela-se, portanto, como um fértil campo de pesquisa na área. Na seção seguinte, discutiremos os respectivos impactos sobre o processo de ensino e aprendizagem da MQ.

\section{Discussão}

Conforme a presente revisão sistemática da literatura, as pesquisas parecem apontar mais para dificuldades do que para avanços. Toda a estrutura matemática da MQ e conceitos contra intuitivos suscitam os estudantes a terem concepções insuficientes e/ou incoerentes dos fenômenos quânticos. Além disso, se reafirmam características apontadas por Rocha et al., (2010), que em vários cursos o ensino de MQ trabalha muito mais com a resolução de problemas envolvendo equações diferenciais e poucos aspectos relacionados aos conceitos fundamentais. Não se observa forte presença de tópicos como a superposição de ondas, superposição de vetores no plano, estados quânticos e observáveis, abordagem dos primeiros postulados da MQ e suas implicações (como por exemplo, o emaranhado quântico, os relógios atômicos e a criptografia quântica).

Tais estudos são importantes para a compreensão do contexto analisado, pois nos estudos apontados, explicações dadas por estudantes acerca de conceitos da MQ marcam a falta de compreensão conceitual - o que confirma a aprendizagem superficial, seja por problema com terminologia, conceito de probabilidade, operadores, função de onda, conceito de incerteza, entre outros.

Os resultados positivos ressonam sobre a presença de novas propostas de ensino no contexto de componentes curriculares, como a forma que o conteúdo é apresentado, materiais didáticos e métodos de ensino. Observa-se que é reforçado o argumento de aproximar inovações didáticas dos componentes curriculares, com o interesse primário de melhorar a compreensão de conceitos quânticos (Baily \& Finkelstein, 2010; Carr \& Mckagan, 2009) - referenciando a partir de agora o próprio artigo. 
Corroborando com esses aspectos, os trabalhos como o de Singh (2001) e Greca et al. (2001), por exemplo, estudam sob diferentes perspectivas, a aquisição de conceitos estruturantes da MQ Moderna, tais como: estado quântico, superposição de estados e evolução temporal. Em contrapartida, outros trabalhos enfocam conceitos mais específicos, sem exceder no principal elemento de teorias físicas: o formalismo matemático. O que está em concordância com outras pesquisas da área (Carvalho Neto, Freire Jr, \& Silva, 2009; Greca \& Herscovitz, 2002; Ostermann \& Moreira, 2000).

Greca et al., (2001) salientam que a abordagem tradicional das disciplinas básicas de física para os cursos de ciências exatas ressalta aspectos históricos com mais características clássicas do que quântica dos fenômenos. Quando recebem informações acerca da MQ, elas são apresentadas na forma de equações complexas sem vínculo com os fenômenos em si. Desta forma, os cursos introdutórios não permitem que o estudante crie uma nova maneira de pensar sobre a realidade e cursos mais avançados (que exigem mais matemática), também não são capazes de discutir as concepções dos alunos acerca dos fenômenos quânticos.

Sobre ferramentas de aprendizagem, é enfatizado a implementação de simulações, ambientes virtuais e interativos decorrentes da possibilidade de motivar os estudantes para o estudo da MQ a partir da visualização dos fenômenos (Müller \& Wiesner, 2002). Müller e Wiesner (2002), da Universidade de Munique, propõem a utilização de softwares educativos no ensino de MQ, em que, segundo os autores, os conteúdos eram compatíveis à população em questão. A proposta foi aplicar, de modo a explorar neste curso, dois softwares do tipo "bancada virtual", um relacionado ao experimento de fenda dupla realizado com feixes de elétrons e outro no interferômetro de Mach-Zahnder. Para tanto, foram utilizados roteiros exploratórios previamente elaborados. Além disso, o curso também inovou abordando os princípios básicos da mecânica ondulatória, sem se referenciar previamente a modelos atômicos como aqueles semiclássicos de Bohr.

No mesmo sentido, Zhu e Singh (2012b), em decorrência ao estudo realizado em componente curricular (Zhu \& Singh, 2012), descrevem o desenvolvimento e implementação de pesquisas baseadas em ferramentas de aprendizagem, como os Tutoriais Interativos de Aprendizagem Quântica, com o objetivo de reduzir as dificuldades dos estudantes com questões relacionadas à medição na MQ. Os conceitos envolvidos são: estado quântico, operadores, observáveis, autovalores, autovetores e os princípios da superposição e da incerteza. Os autores relatam que os estudantes que usam ferramentas, baseadas em pesquisas de aprendizagem, obtém resultado significativamente melhor do que aqueles que não utilizam.

A compreensão equivocada dos fenômenos quânticos não apenas cria problemas conceituais, como também pode obstruir o entendimento de como a interpretação padrão (Copenhague) implica que o próprio ato de observação realmente cria o estado em vez de meramente medi-lo (Montenegro \& Pessoa Jr., 2002; Zhu \& Singh, 2012). Uma compreensão da observação como medida envolve interação, questões interpretativas, cálculos sem excesso; buscando também, sempre que possível, verificar como estava 
ocorrendo didaticamente (metodologicamente) o ensino da MQ, essenciais para desenvolver entendimento mais profundo da teoria.

Notamos, a partir da leitura dos artigos publicados nas bases de dados consultadas, a necessidade de se reavaliar os currículos dos cursos superiores de $M Q$, especificamente no tocante a sua característica intensamente matemática, pois ainda são vários os cursos de MQ que trabalha muito mais com a resolução de problemas envolvendo equações diferenciais e poucos aspectos relacionados aos conceitos fundamentais.

Entre os estudos selecionados, em relação aos reais impactos das novas propostas de ensino de $M Q$, vemos que o grande desafio dos educadores e pesquisadores da área é criar uma forma na qual os conteúdos estejam presentes no componente curricular, alertando para a necessidade de ampliação do ensino tradicional para a ideia de uma física como cultura ampla, capaz de construir uma visão de mundo científica, constituindo-se referencial importante para formação dos estudantes.

Aproximando essa discussão para o ensino de MQ no Brasil, até o momento, são poucas as publicações nacionais no contexto de um componente curricular, apenas dois estudos, estando a maior parte concentrada nos Estados Unidos, impossibilitando comparações específicas.

Os achados dos estudos brasileiros indicam elevada negligência quanto à abordagem de questões conceituais e interpretativas da MQ, tendo melhores resultados quando utilizado um mínimo de ferramentas matemáticas e priorizado a dimensão histórico-epistemológica sem recair em simplificações exageradas. Portanto, embora não haja dados que representem as dificuldades dos estudantes em todas as regiões brasileiras são demarcadas limitações comuns entre os estudos da presente investigação.

Além da escassez, existe pouca padronização metodológica em relação à estrutura do processo de ensino-aprendizagem investigado, o que torna difícil a comparação de resultados. As diferenças metodológicas contribuem para a grande diversidade de possibilidades para o ensino de MQ. Entretanto, apesar de todos os problemas, verifica-se a necessidade comum de investir na compreensão conceitual com atenção aos impactos gerados ao processo de formação dos estudantes.

\section{Conclusões e Implicações}

Os estudos analisados nessa revisão da literatura nos possibilitaram explicitar: 1) contribuições para a compreensão das repercussões das implementações didáticas no processo de ensino-aprendizagem na formação dos estudantes na área de MQ; 2) implicações para a (re)elaboração da estrutura de componentes curriculares para o ensino de MQ. Além disso, destacamos alguns pontos que consideramos importantes contribuições para a produção de novos conhecimentos sobre o assunto.

Duas discussões bem demarcadas nos estudos foram a necessidade de investigar as concepções dos fenômenos quânticos dos estudantes e a relevância de explorar as relações decorrentes das práticas de ensino com foco no desenvolvimento das concepções desses sobre MQ. Observou-se que diferentes abordagens pedagógicas têm impactos 
diferenciados no processo cognitivo do estudante. A maioria dos estudantes apresentou as mesmas dificuldades, por exemplo, dissociar a Física Clássica da MQ. No entanto, é preciso tomar esses resultados com cautela, já que as análises referem-se apenas a um contexto específico.

Em nossa delimitação de artigos, utilizamos revisões anteriores da literatura para descrever os diversos aspectos que estão presentes na área de pesquisa em questão e que foram atualizados neste artigo. Diante dos achados desta revisão sistemática, recomendase o desenvolvimento de estudos cuidadosamente desenhados para esclarecer a relação entre a implementação de inovações didáticas e as necessidades e o interesse dos estudantes, a partir de aplicação de conceitos e procedimentos físicos em situações que lhes façam sentido, em uma perspectiva contemporânea, conceitual, epistemológica e de transposição didática, o que também não exclui que em determinados momentos o professor faça breves apresentações e explicações mais expositivas (Moreira, 2018).

Há necessidade de pesquisas que explicitem o referencial de ensinoaprendizagem em que estão sendo formuladas. Muitas parecem mais reflexões sobre a experiência dos seus autores com determinada prática, ou sobre as preferências pessoais para determinado enfoque. Não há indicadores adequados para o entendimento e reprodução posterior das propostas. Em vários trabalhos apresentados, está ausente a discussão explícita da metodologia utilizada; outros só nomeiam uma metodologia ou ainda a apresentam subentendidas. Essa ausência reafirma outro problema: déficit no processo metodológico fundamental, vinculado a uma falta de conhecimento tanto sobre metodologia de pesquisa como de sua utilização no processo de investigação. É um problema pertinente a didática no Ensino de Física - questões semelhantes foram apontadas por Jiménez-Aleixandre (1998) em uma revisão mais geral sobre pesquisas internacionais na área de ensino de Ciências.

Conforme afirma Santos e Sánchez (2000), as técnicas de pesquisa científica, sejam quantitativas ou qualitativas, não podem ser entendidas em si mesmas, sua compreensão está no método. O pesquisador deve ter a ideia clara de que é o processo da pesquisa que qualifica as técnicas e os instrumentos necessários para a elaboração do conhecimento, o que confirma que as opções técnicas dependem dos caminhos a serem percorridos e dos procedimentos a serem desenvolvidos. Essas questões remetem-nos à reflexão sobre como buscar meios e alternativas que busquem sanar tais divergências entre o esperado e o que realmente ocorre no ensino de MQ.

Os artigos científicos discutidos no presente trabalho revelam que a compreensão dos princípios da MQ exige a inter-relação entre conceitos, ferramentas matemáticas básicas e a dimensão epistemológica configurada ao fornecer elementos que permitam aos estudantes reflexões mais profundas sobre a atividade científica e sua ontologia, enfraquecendo consideravelmente o mito das verdades definitivas (Pietrocolla, 2003). A epistemologia na MQ lida com "atitudes realistas (o mundo existe independente do sujeito que o percebe) ou positivistas (todo o nosso conhecimento deriva dos nossos sentidos)" (Ostermann \& Prado, 2005, p. 194). Segundo Ostermann e Prado (2005), 
qualquer tentativa de discussão dos conceitos envolvidos na MQ traz à tona elementos de sua epistemologia fundamentais para a compreensão dos fenômenos quânticos.

O professor deve aprimorar suas atividades para a explicação de conceitos, considerando a dinâmica de entendimento dos estudantes, porém, sem descartar o formalismo matemático. Nesse quesito, se marca a importância de adequadas estratégias de ensino. Desenvolver uma compreensão da MQ é um processo que demanda tempo e ocorre a longo prazo (Deslauriers \& Wieman, 2011). O tempo de ensino é fundamental para o sucesso na aprendizagem da MQ. O domínio conceitual do conteúdo tornase bastante instável em um curto período de exposição e, portanto, novos meios e diferentes abordagens pedagógicas de ensino criam maiores probabilidades para uma efetiva aprendizagem.

Finalmente, na interlocução com o legado da literatura (Cuesta, 2018; Rocha, Herscovitz, \& Moreira, 2018), percebe-se que são diversas as inquietações e que alguns desafios, dilemas e dificuldades que compartilhamos no passado ainda permanecem no estágio atual do ensino de MQ nos cursos de graduação em Física. O conhecimento gerado pela presente revisão constitui um recorte que contribui para uma maior compreensão da situação atual dos componentes curriculares, como um dos segmentos mais importantes do processo formativo dos estudantes e, de maneira mais ampla, resulta em subsídios para orientar a tomada de decisão no tocante à formulação de cursos de MQ mais adequados à realidade de sala de aula. Ainda que não tenha sido objetivo do presente estudo esgotar o assunto, fica a convicção de que a revisão efetuada oferece suporte teórico e empírico para o argumento de que trabalhos de intervenção didática em diferentes abordagens, baseados em uma reflexão desenvolvida a partir de diferentes referenciais de leitura e enfoques teóricos, podem abrir novos rumos para os desafios colocados pelo processo de ensino-aprendizagem de MQ.

\section{Agradecimentos}

Os autores agradecem à Coordenação de Aperfeiçoamento de Pessoal de Nível Superior (CAPES) pelo financiamento da pesquisa.

\section{Referências}

André, M. (2001). Pesquisa, Formação e Prática Docente. In M., André. O papel da pesquisa na formação e na prática dos professores. Papirus.

Akarsu, B. (2010). Einstein's redundant triumph "quantum physics": An extensive study of teaching/learning quantum mechanics in college. Lat. Am. J. Phys. Educ.,3(2), 273285.

Bao, L., Jolly, P., \& Redish, E. (1996). Student difficulties with Quantum Mechanics. Oral Communication, AAPT Summer meeting, Phoenix, Aug. 8-6. https://doi. org/10.1080/0950069980200404 
Barros, M. A., \& Freire Jr., O. (2011). O ensino/aprendizagem de Mecânica Quântica na licenciatura em Física: Um estudo de caso. In IV Encontro Estadual de Ensino de Física - RS, Porto Alegre. http://www.if.ufrgs.br/mpef/4eeefis/sistemas/busca_publicacao. php?trabalho=143

Bennett, J., Lubben, F., Hogarth, S., \& Campbell, B. (2005). Systematic reviews of research in Science Education: rigour or rigidity? International Journal of Science Education, London, 27(4), 387-406. https://doi.org/10.1080/0950069042000323719

Carvalho, A. X. S. (2017). Uma Proposta de Unidade de Ensino sobre a Antiga Teoria Quântica como Instrumento Pedagógico Alternativo. Dissertação. Universidade Federal de Mato Grosso, CUIABÁ - MT. http://www1.fisica.org.br/mnpef/sites/default/files/ Dissertacao-Alessandro.pdf

Carvalho Neto, R. A. (2016). Internalização do significado da Teoria Quântica do Processo de Medida de acordo com a interpretação da complementaridade. (C3331i) [Tese de doutorado, Programa de Pós-Graduação em Ensino, Filosofia e História das Ciências, Universidade Federal da Bahia e Universidade Estadual de Feira de Santana,]. $271 \mathrm{p}$.

Carvalho Neto, R. A., Freire Jr, O., \& Silva, J. L. P. B. (2009). Improving students' meaningful learning on the predictive nature of quantum mechanics. Investigações em Ensino de Ciências, 14(1), 65-81.

Chaves, F. G. (2010). Uma proposta de inserção de conteúdos de Mecânica Quântica no ensino médio por meio de um curso de capacitação para professores em atividade. Dissertação. Universidade de Brasília.

Cuesta-Beltrán, Y. J. (2018). Estado del arte: Tendências en la enseñanza de la física cuántica entre 1986 y 2016. TED, 44(jul-dic), 147-166. https://doi.org/10.17227/ted. num44-8995

Deslauriers, L., \& Wieman, C. (2011). Learning and retention of quantum concepts with different teaching methods, Physical Review Special Topics - Physics Education Research 7(1), 010101. https://doi.org/10.1103/PhysRevSTPER.7.010101

Didiş, N., Eryilmaz, A., \& Erkoç, S. (2010). Pre-service Physics Teachers'Comprehension of Quantum Mechanical Concepts. Eurasia Journal of Mathematics, Science \& Technology Education, 6(4), 227-235. https://doi.org/10.12973/ejmste/75243

Dios, J. G., \& Santamaría, A. B. (2007). Revisión sistemática y metanálisis (I): Conceptos básicos. Evidencias em Pediatría. 3(4),107. 1-10

Dominguini, L. (2012). Física moderna no Ensino Médio: Com a palavra os autores dos livros didáticos do PNLEM. Revista Brasileira de Ensino de Física. 34(2) 1-7.

Fanaro, M. A., Arlego, M., \& Otero, M. R. (2007). El Método de Caminos Múltiples de Feynman como Referencia para Introducir los Conceptos Fundamentales de la 
Mecánica Cuántica en la Escuela Secundaria. Caderno Brasileiro de Ensino de Física, 24(2), 233-260.

Ferreira, R. M. (2013). Física moderna: Divulgação e acessibilidade no ensino médio através das histórias em quadrinho. Dissertação. Universidade Federal de Alagoas, Maceió.

Freire Jr., O. Pessoa Jr., O., \& Bromberg, J. L. (2010). (Orgs.) Teoria Quântica: Estudos Históricos e Implicações Culturais. EDUEPB. Livraria da Física.

Greca, I. M., \& Freire, O. (2014). Meeting the Challenge: Quantum Physics in Introductory Physics Courses. In Matthews, M. R. (Ed.) International Handbook of Research in History, Philosophy and Science Teaching. Springer, (Vol. 1), pp. 183-209.

Greca, I. M., \& Herscovitz, V. E. (2002). Construyendo significados en mecánica cuántica: fundamentación y resultados de una propuesta innovadora para su introducción en el nivel universitario. Enseñanza de las Ciencias, 20(2), 327-338. https://www.raco.cat/ index.php/Ensenanza/article/view/21818.

Greca, I. M., \& Santos, F. M. T. (2020). Research Methods in Science Education in Latin America: How we are Carrying out Research in this Last Decade. In C. N. El-Hani, M. Pietrocola, E. F. Mortimer, \& M. R. Otero (Orgs.). Science Education Research in Latin America. Brill. pp. 20-39

Jiménez-Aleixandre, M. P. (1998). Onde vai a pesquisa em Didática das Ciências: Estudos dos discursos na aula. In Atas do IV Encontro de Pesquisa em Ensino de Física. Cd-Rom SBF.

Johnston, I. D., Crawford, K., \& Fletcher, P. R. (1998). Student difficulties in learning quantum mechanics. Int. J. Sci. Educ., 20(4), 427-446. https://doi. org/10.1080/0950069980200404

Krijtenburg-Lewerissa, K., Pol, H. J., Brinkman, A., \& Van Joolingen, W. R. (2017). Insights into Teaching Quantum Mechanics in Secondary and Lower Undergraduate Education. Phys. Rev. Phys. Educ. Res. 13(1) 010109. 1-21

Lüdke, M., \& André, M. (1986). Pesquisa em Educação: Abordagens Qualitativas. Editora pedagógica e universitária - EPU.

Machado, D. I., \& Nardi, R. (2006). Construção de conceitos de Física moderna e sobre a natureza da Ciência com suporte da hipermídia. Revista Brasileira de Ensino de Física, 28(4), 472-485.

Marandino, M. (2003). A prática de ensino nas licenciaturas e a pesquisa em ensino de Ciências: Questões atuais. Cad. Bras. Ens. Fís. 20(2), 168-193.

Meltzer, D., \& Thornton, R. (2012). Resource letter ALIP-1: Active-learning instruction in Physics. Am J Phys, 80(6), 478-496. https://doi.org/10.1119/1.3678299 
Moreira, M. A. (2018). Uma análise crítica do ensino de Física. Estud. av., 32(94), 73-80. https://doi.org/10.1590/s0103-40142018.3294.0006

Müller, R., \& Wiesner, H. (2002). Teaching quantum mechanics on an introductory level. American Journal of Physics, 70(3), 200-209. http://www.fisica.net/quantica/ ebooks/MULLER\%20-\%20Teaching\%20quantum\%20mechanics\%20on\%20an\%20 introductory\%20level.pdf

Oliveira, F. F., Vianna, D. M., \& Gerbassi, R. S. (2007). Física Moderna no Ensino Médio: O que dizem os professores. Revista Brasileira de Ensino de Física, 29(3), 447-454.

Ostermann, F., \& Moreira, M. A. (2000). Uma revisão bibliográfica sobre a área de pesquisa "Física Moderna e Contemporânea no Ensino Médio". Investigações em Ensino de Ciências, 5(1), 23-48. https://www.if.ufrgs.br/cref/ojs/index.php/ienci/article/ view/600/390

Ostermann, F., \& Prado, S. D. (2005). Interpretações da mecânica quântica em um interferômetro virtual de Mach-Zehnder. Revista Brasileira de Ensino de Física. 27(2), 193-203. http://www.scielo.br/scielo.php?pid=S1806-11172005000200003\&script=sci_ abstract\&tlng=pt

Pacheco, J. A. (2001). Currículo: Teoria e prâxis. 2.ed. Porto.

Pantoja, G. F., Moreira, M. A., \& Herscovitz, V. E. (2011). Uma revisão da literatura sobre a pesquisa em ensino de mecânica quântica no período de 1999 a 2009. Revista Brasileira de Ensino de Ciência e Tecnologia, 4(3), 1-34.

Paulo, I. J. C., \& Moreira, M. A. (2011). O problema da linguagem e o ensino da mecânica quântica no nível médio. Ciênc. educ. (Bauru) 17(2), 421-434.

Pereira, R. O., \& Aguiar, O. (2006). Ensino de Física no nível Médio: Tópicos de Física Moderna e Experimentação. Revista Ponto de Vista, 3(1), 65-81.

Pereira, A. P., \& Ostermann, F. (2009). Sobre o ensino de física moderna e contemporânea: uma revisão da produção acadêmica recente. Investigações em Ensino de Ciências, 14(3), 393-420.

Pereira, F. C., \& Schumacher, E. (2013). Hands-on-tec e a Aprendizagem Significativa de conceitos de Física Moderna e Contemporânea. Aprendizagem Significativa em Revista, 3(2), 22-34.

Pessoa Jr., O. (2003). Conceitos de Física Quântica. 1 ed., vol. 1. Editora Livraria de Física.

Pietrocola, M. (2003). A História e a Epistemologia no Ensino de Ciências: dos processos aos modelos de realidade na educação científica. In A. M. R., Andrade (Org.). Ciência em Perspectiva. Estudos, Ensaios e Debates. MAST/SBHC, pp. 133-149. 
Pospiech, G., \& Schöne, M. (2014). Quantum Physics in Teacher Education. In G. Burra, B. G. Sidharth, M. Michelini, \& L. Santi, (Eds). Frontiers of Fundamental Physics and Physics Education Research. Springer Proceedings in Physics, 145 (1), 407-416.

Rocha, C. R., Moreira, M. A., \& Herscovitz, V. E. (2010). Introdução à Mecânica Quântica: Uma proposta de minicurso para o ensino de conceitos e postulados fundamentais. Revista Brasileira de Ensino de Ciência e Tecnologia, 3(1). https://lume. ufrgs.br/handle/10183/132503

Rocha, C. R., Herscovitz, V. E., \& Moreira, M. A. (2018). Uma revisão da literatura em publicações de 2010 a 2016 sobre o ensino de conceitos fundamentais de Mecânica Quântica. Latin-American Journal of Physics Education, 12(1), 1-20.

Santos, M. A. B. A. (2012). Mecânica Quântica no processo de formação de licenciandos em Física: Um estudo de caso. [Tese de Doutorado, Universidade Federal da Bahia, PróReitoria de Pesquisa e Pós-Graduação].

Santos F. O. J., \& Sánchez G. S. (2000). Pesquisa educacional: Quantidade-qualidade. Cortez Editora.

Silva, A. C., \& Almeida, M. J. P. M. (2011). Física quântica no ensino médio: o que dizem as pesquisas. Caderno Brasileiro de Ensino de Física, 28(3), 624-653. http://dx.doi. org/10.5007/2175-7941.2011v28n3p624

Singh, C., \& Marshman, E. (2015). Review of student difficulties in upper-level quantum mechanics. Physical review special topics - Physics Education Research, 11, 020117. https:// arxiv.org/abs/1504.02056

Styer, D. (1996). Common misconceptions regarding quantum mechanics, Am. J. Phys. 64(1). 1-8. http://www.physics.umd.edu/courses/Phys401/bedaque07/misconnzz.pdf

Teixeira, E. S., Greca, I. \& Freire, O. (2012a). The History and Philosophy of Science in Physics Teaching: a research synthesis of didactic interventions. Science and Education, 21(6), 771-796. https://link.springer.com/article/10.1007/s11191-009-9217-3

Teixeira, E. S., Greca, I., \& Freire, O. (2012b). Uma revisão sistemática das pesquisas publicadas no Brasil sobre o uso didático de História e Filosofia da Ciência no Ensino de Física. In L. O. Q. Peduzzi, A. F. P. Martins, \& J. M. Hidalgo, (Orgs.) Temas de História e Filosofia da Ciência no Ensino. EDUFRN.

Villani, A., \& Guridi, V. (2008). Professor - Pesquisador de sua Prática: Dificuldades e motivações. VIII Congreso Internacional sobre Investigación en la Didáctica de las Ciencias. Revista Eureka sobre Enseñanza y Divulgación de las Ciencias, 5(3), 1630-1633.

Zollman, D., Rebello, S., \& Hogg, K. (2002). Quantum physics for everyone: Hands-on activities integrated with technology.Am.J.Phys. 70(3), .https://eric.ed.gov/?id=EJ652830 
Zhu, G., \& Singh, C. (2012b). Improving students' understanding of quantum measurement II. Development of research- based learning tools. Physical Review Special Topics - Physics Education Research, 8(1), 010118, 1-13. https://doi.org/10.1103/ PhysRevSTPER.8.010118

\section{Referências dos artigos selecionados para análise final}

A1 - Singh, C. (2001). Student understanding of quantum mechanics. American Journal of Physics, 69(8), 885-895. https://doi.org/10.1119/1.1365404

A2 - Greca, I. M., Moreira, M. A., \& Herscovitz, V. E. (2001). Uma proposta para o ensino de mecânica quântica. Rev. Bras. Ensino Fís., 23(4), 444-457. http://www.scielo. br/scielo.php?script=sci_arttext\&pid=S1806-11172001000400010

A3 - Müller, R., \& Wiesner, H. (2002). Teaching quantum mechanics on an introductory level. Am. J. Phys. 70, 200. https://doi.org/10.1119/1.1435346

A4 - Montenegro, R. L., \& Pessoa Jr., O. (2002). Interpretações da Teoria Quântica e as concepções dos estudantes do curso de Física. Investigações em Ensino de Ciências, 7(2), 107-126. https://www.if.ufrgs.br/cref/ojs/index.php/ienci/article/view/564/356

A5 - Carr, L. D., \& Mckagan, S. B. (2009). Graduate quantum mechanics reform. American Journal of Physics, 77, 308. https://arxiv.org/abs/0806.2628

A6 - Baily, C., \& Finkelstein, N. D. (2010). Teaching and understanding of quantum interpretations in modern physics courses. Physical review special topics - Physics Education Research,6,010101-1-010101-11.https://journals.aps.org/prper/pdf/10.1103/ PhysRevSTPER.6.010101

A7 - Deslauriers, L., \& Wieman, C. (2011). Learning and retention of quantum concepts with different teaching methods. Physical review special topics - Physics Education Research, 7(1), 010101-1-010101-6 . https://eric.ed.gov/?id=EJ921976

A8 - Zhu, G., \& Singh, C. (2012a). Improving students' understanding of quantum measurement.I.Investigation ofdifficulties.PhysicalreviewspecialtopicsPhysics-Education Research, 8(1), 010117-1-010117-8. https://doi.org/10.1103/PhysRevSTPER.8.010117

A9 - Didis, N. (2012a). The analysis of analogy use in the teaching of introductory quantum theory. Chem. Educ. Res. Pract., 16, 355-376. http://dx.doi.org/10.1039/ C5RP00011D 
Rafaelle da Silva Souza

(1) https://orcid.org/0000-0001-6713-2292 Instituto Federal de Educação, Ciência e Tecnologia da Bahia campus Seabra Professora de Física Seabra, Bahia, Brasil rafaellessouza@gmail.com

Ileana Maria Greca

(ㄷ) https://orcid.org/0000-0003-3674-7985

Universidad de Burgos Departamento de Didáticas Especificas Burgos, Espanha imgreca@ubu.es Indianara Silva

(1) https://orcid.org/0000-0002-2124-6435 Universidade Estadual de Feira de Santana Departamento de Física Feira de Santana, Bahia, Brasil indianara.slima@gmail.com

Elder Sales Teixeira

https://orcid.org/0000-0002-6013-2043 Universidade Estadual de Feira de Santana Departamento de Física Feira de Santana, Bahia, Brasil eldersate@gmail.com

Submetido em 02 de junho de 2020 Aceito em $\mathbf{2 5}$ de setembro de 2020 Publicado em 14 de janeiro de 2021 